\title{
Monitoring the acute phase response to vaso-occlusive crisis in sickle cell disease
}

\author{
J Stuart, P C W Stone, N O Akinola, J R Gallimore, M B Pepys
}

\begin{abstract}
Aims-To identify suitable acute phase proteins as objective markers of tissue ischaemia during painful vaso-occlusive crises in sickle cell disease.

Methods-The prodromal and established phases of 14 vaso-occlusive crises were studied longitudinally in 10 patients with sickle cell anaemia. Automated solid phase enzyme immunoassays were used to measure the fast responding acute phase proteins C-reactive protein and serum amyloid $A$ protein. Slower responding glycoproteins (fibrinogen, orosomucoid, sialic acid and concanavalin-A binding) were measured in parallel. Results-C-reactive protein and serum amyloid $A$ protein increased early in crisis, sometimes within the early (prodromal) phase. Crises that resolved within 24 hours in hospital showed a minor and transient rise compared with crises that required treatment for four days or more. In eight crises treated by patients at home the acute phase response ranged from minor to a level consistent with extensive tissue ischaemia.
\end{abstract}

Conclusions-Sensitive enzyme immunoassays for C-reactive protein and serum amyloid $A$ protein are of potential value for monitoring the onset of tissue ischaemia in sickle cell crisis and for confirming subsequent resolution.

(F Clin Pathol 1994;47:166-169)

Department of Haematology, The Medical School, The University of

Birmingham,

Birmingham B15 2TT

J Stuart

P C W Stone

N O Akinola

Immunological

Medicine Unit

Department of

Medicine, Royal

Postgraduate Medical

School,

Hammersmith

Hospital, London

J R Gallimore

M B Pepys

Correspondence to:

Professor J Stuart

Accepted for publication

7 September 1993
Patients with sickle cell disease have intermittent painful crises caused by occlusion of the microcirculation with sickled cells. Crises vary considerably in severity, ranging from mild episodes that respond at home to simple analgesics and oral rehydration, to extensive tissue infarction requiring parenteral opiates and intravenous fluids in hospital. In some episodes it is difficult to confirm that tissue infarction has occurred, and in others, to establish the time of onset as $58 \%$ of patients experience a prodromal phase for several hours, and sometimes days, beforehand. ${ }^{1}$ During established crisis, pain may shift from site to site, the resolution of crisis may be protracted, and there may be complicating infection. Objective criteria to monitor the progress of crisis, guide the duration of treatment, and mark the end of crisis are required.
Quantitative measurement of the blood concentration of acute phase proteins is a valuable indicator of the onset, extent, and response to treatment of the inflammatory response to tissue damage. Such measurements may be of value for determining the onset of vaso-occlusive crisis ${ }^{2}$ and for detecting subclinical episodes of tissue ischaemia that occur in the asymptomatic steady state between crises. ${ }^{34}$

We therefore studied the prodromal and established phases of a total of 14 vasoocclusive crises in 10 patients to determine the value of new sensitive immunoassays for the fast responding proteins C-reactive protein and serum amyloid A protein (SAA) which show an increase in blood concentration within six to 10 hours of tissue injury. ${ }^{56}$ To investigate longer term changes, we studied the individual slow responding glycoproteins fibrinogen and orosomucoid ( $a_{1}$-acid glycoprotein), which show an increase within 24-48 hours of tissue injury. ${ }^{6} \mathrm{We}$ also studied plasma sialic acid and concanavalin-A binding (con-A) as a measure of multiple slow responding glycoproteins.

\section{Methods}

Ten patients with severe sickle cell anaemia were studied longitudinally both when asymptomatic during the steady state and during a total of 14 painful crises. Eight crises were treated by the patient at home, using oral analgesics and fluids, with a research nurse visiting the patient to collect blood samples. In six crises the patient was admitted to hospital under the care of a consultant haematologist and serial blood samples were again collected, initially in hospital and then at home. All patients had been trained to keep a diary of symptoms during the steady state and to telephone whenever they had a premonition of sickle crisis. ${ }^{2} \mathrm{~A}$ home visit was then made to collect the first blood sample (day 1) in this prodromal phase of crisis.

SAA was measured using an automated monoclonal-polyclonal solid phase sandwich enzyme immunoassay run on the Abbott $\mathrm{IM}_{\mathrm{x}}$ instrument (Abbott Laboratories, North Chicago, IL 60064, USA) (Pepys et al, unpublished observation). The assay was standardised with the prospective WHO International Reference Standard for SAA Immunoassay, which is currently undergoing its international collaborative study. This standard consists of a pool of acute phase serum in which the SAA concentration was 
established by radial immunodiffusion assay calibrated with an acute phase high density lipoprotein preparation, the SAA content of which was determined by sodium dodecyl sulphate polyacrylamide gel electrophoresis (SDS-PAGE) analysis compared with standards of pure SAA.

The calibrators and controls were prepared from a stabilised denatured SAA concentrate. The assay has a potential sensitivity of $0.2 \mathrm{mg} / \mathrm{l}$ but, because it is less reproducible in this range, values below $1 \mathrm{mg} / \mathrm{l}$ are reported here as $<1 \mathrm{mg} / 1$. The upper limit is $300 \mathrm{mg} / \mathrm{l}$ and inter- and intra-assay coefficients of variation are $3 \cdot 9-7 \cdot 0 \%$ across the assay range. Samples containing SAA at concentrations above the upper assay limit were rerun at higher dilutions. Among 100 healthy normal subjects, the mean (SD) SAA concentration was $3.7(3.6) \mathrm{mg} / \mathrm{l}$ and the median (range) was $3.0(0.7-26.4) \mathrm{mg} / \mathrm{l}$.

Serum C-reactive protein was measured in an automated monoclonal antibody solid phase sandwich enzyme immunoassay on the Abbot $\mathrm{IM}_{\mathrm{x}}$ instrument (Pepys et al, unpublished observations). The assay was calibrated with the WHO International Reference Standard for C-reactive Protein Immunoassay (85/506); calibrators and controls were prepared from isolated C-reactive protein. ${ }^{7}$ The assay has a sensitivity of $0.05 \mathrm{mg} / \mathrm{l}$, upper limit of $30 \mathrm{mg} / \mathrm{l}$, and inter- and intra-assay coefficients of variation of $<10.0 \%$ across the assay range. Samples containing C-reactive protein at concentrations above the upper assay limit were rerun at higher dilutions. The median normal value is $0.8 \mathrm{mg} / 1 ; 90 \%$ of healthy subjects have concentrations below $3 \mathrm{mg} / 1$ and $99 \%$ are below $10 \mathrm{mg} / 1 .{ }^{8}$

Plasma fibrinogen and serum orosomucoid were measured using radial immunodiffusion kits (The Binding Site Ltd, Birmingham). Sialic acid was measured on citrated plasma, using an enzyme assay test kit (Kyokuto Pharmaceutical Industrial Co Ltd, Tokyo) based on the method of Sugahara et al, ${ }^{9}$ and expressed as percentage activity relative to the manufacturer's lyophilised control serum, with correction for dilution by the liquid anticoagulant. Con-A was measured on citrated plasma by laser nephelometry based on the method of Warren et $a l^{10}$ and expressed similarly.

Significance was determined by the nonparametric Wilcoxon matched pairs signed ranking test.

Table 1 Tests of slow responding acute phase glycoproteins at three stages of sickle cell crisis (Results are given as median (25th-75th centiles) and compared with corresponding steady state values for the same patients)

\begin{tabular}{llllc}
\hline & Steady state & Day 1 & Days 3-5 & Days 6-7 \\
\hline Fibrinogen $\mathrm{g} / \mathrm{l}$ & $3 \cdot 7$ & $3 \cdot 5^{\star}$ & $4 \cdot 3 \dagger$ & $4 \cdot 5$ \\
(10 crises) & $(3 \cdot 3-4 \cdot 1)$ & $(2 \cdot 9-3 \cdot 6)$ & $(3 \cdot 9-5 \cdot 3)$ & $(4 \cdot 0-5 \cdot 8)$ \\
Orosomucoid $\mathrm{g} / 1$ & $1 \cdot 0$ & $0 \cdot 8^{\star}$ & $1 \cdot 1$ & $1 \cdot 2 \dagger$ \\
(10 crises) & $(0 \cdot 8-1 \cdot 1)$ & $(0 \cdot 6-0 \cdot 9)$ & $(0 \cdot 8-1 \cdot 4)$ & $(0 \cdot 9-1 \cdot 4)$ \\
Sialic acid $\%$ & 60 & 57 & 69 & $74 \dagger$ \\
(8 crises) & $(59-62)$ & $(55-61)$ & $(61-70)$ & $(65-75)$ \\
Con-A \% & 76 & $68^{\star}$ & 80 & $84 \dagger$ \\
(8 crises) & $(72-77)$ & $(64-76)$ & $(79-83)$ & $(77-87)$ \\
\hline
\end{tabular}

${ }^{\star} \mathrm{p}<0.05 v$ steady state

tp $<0.05 v$ day 1 .

\section{Results}

The four tests of slow responding acute phase glycoproteins were studied serially during eight to 10 crises. There was a significant rise on days 3-5 or 6-7 of crisis compared with day 1 (table 1). Day 1 values showed a slight fall compared with steady state values for the same patients. Results were similar whether single glycoproteins (fibrinogen and orosomucoid) or tests of multiple glycoproteins (sialic acid and con-A) were studied.

The fast responding acute phase proteins C-reactive protein and SAA were also studied in the above (plus four additional) crises in the same 10 patients. Of six crises treated in hospital (table 2), three crises resolved within 24 hours; two of these patients were then discharged but the third developed a vitreous haemorrhage in the left eye and remained in hospital for a total of 11 days. The remaining three crises required hospital treatment for four, five, and 10 days. Case 1 had a urinary tract infection and case 4 (crisis 2) became febrile on day 2 and developed $x$ ray evidence of chest infection. There was no apparent infection in association with the other crises, whether treated in hospital or at home.

Patients with crises that resolved within 24 hours in hospital (table 2) demonstrated a minor acute phase rise in C-reactive protein and SAA compared with the greater rise in patients admitted for four days or more. Patients who treated their crises at home (table 3) showed a varying degree of acute phase response, ranging from a minimal rise in C-reactive protein and SAA, to concentrations that matched those observed in patients admitted to hospital for four days or more. Whether treated in hospital or at home, the day 1 specimens reflected the earliest identifiable stage of crisis (prodromal phase) and the

Table 2 Serial values for $C$-reactive protein and $S A A$ during six crises in five patients treated in hospital for 24 hours (cases 1-2) or for four to 11 days (cases 3-5) (Steady state values (median and range for nine occasions) are also shown for each patient)

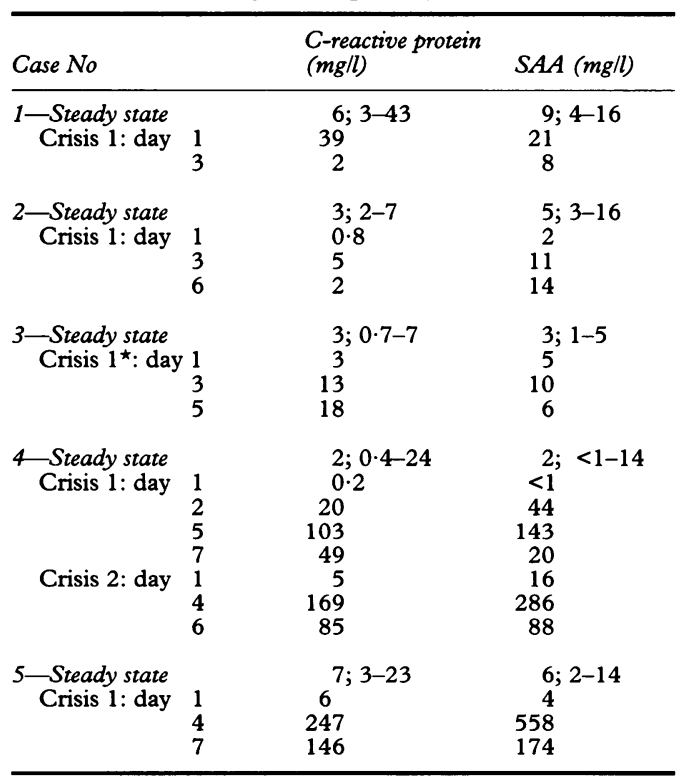

^Severe pain for 24 hours only; followed by left vitreous haemorrhage treated for 11 days in hospital. 
Table 3 Serial values for C-reactive protein and SAA during eight crises in five patients treated at home (Steady state values (median and range for nine occasions) are also shown for each patient)

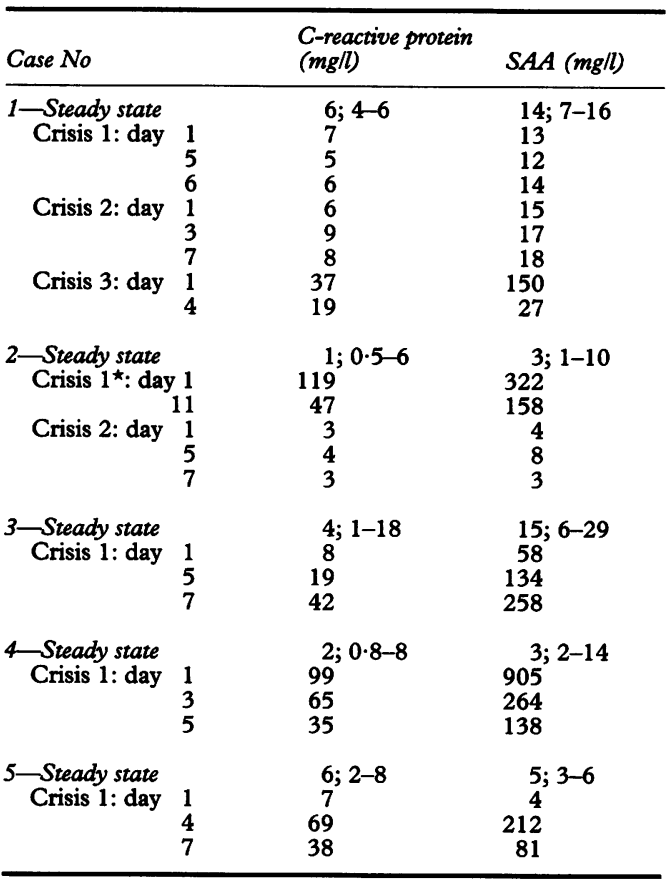

^Eight days' fairly severe pain at home with subsequent $x$ ray changes consistent with left tibial infarct.

C-reactive protein and SAA values tended to increase thereafter. In four crises (three of which were treated at home), the peak Creactive protein and SAA concentrations had already been reached by day 1 .

\section{Discussion}

Previously identified markers for the onset of vaso-occlusive crises in sickle cell disease have included the release of lactate dehydrogenase, or its isoenzymes, from infarcted bone marrow ${ }^{11}$ and the release of creatine kinase from infarcted muscle. ${ }^{12}$ An increase in blood concentration of the slow responding acute phase proteins fibrinogen and orosomucoid has also been demonstrated in crisis. ${ }^{213}$ Tests which reflect change in several slow responding glycoprotein, such as those for plasma viscosity $^{214}$ and the erythrocyte sedimentation rate modified by the substitution of normal erythrocytes for rouleaux inhibiting sickle cells, ${ }^{15}$ have also shown a rise during crisis.

Sialic acids form the terminal sugars of most plasma glycoproteins and thus of most acute phase proteins, with the exception of Creactive protein and SAA which are not glycoproteins. Measurement of total sialic acid therefore reflects the overall concentration of multiple, slow responding acute phase proteins. ${ }^{16}$ Similarly, the plant lectin con-A will bind and precipitate most acute phase proteins that are glycoproteins and thus the slower responding proteins. ${ }^{10}$ In this study both sialic acid and con-A binding showed similar kinetics to the rise in fibrinogen and orosomucoid. Tests that reflect the rise in multiple acute phase proteins therefore offered no advantage for monitoring sickle cell crisis over measurement of individual proteins. A similar conclusion can be drawn for the measurement of plasma viscosity. ${ }^{2}$ On day 1 of crisis (table 1) there was an apparent fall in glycoprotein concentration compared with steady state values, but this probably reflects subclinical ischaemic episodes during the steady state which are known to cause intermittent elevations in acute phase proteins, even when patients are asymptomatic. ${ }^{34}$

These results, together with the known kinetics of the above slow responding proteins, indicate that tissue infarction was well advanced when the tests became abnormal and a faster responding acute phase protein is required. We therefore used new and highly sensitive immunoassays for C-reactive protein and SAA. When crises were classified into those treated in hospital for 24 hours only, compared with four days or more, the rapidly resolving crises were associated with a minor rise in C-reactive protein or SAA to values comparable with peak values recorded during the asymptomatic steady state when subclinical ischaemic episodes may occur. The more protracted crises were associated with higher concentrations of both proteins. While SAA showed the quantitatively greater increase during crisis, the increase did not occur earlier than that of C-reactive protein.

Patients who treated their crises at home showed an acute phase response that varied in magnitude from a minimal response to one that approached the value found in patients admitted for four days or more. This agrees with our clinical experience that some patients endure substantial and prolonged discomfort during crisis rather than be admitted to hospital. The number of hospital admissions is thus not an accurate reflection of disease severity.

Our patients had been trained to recognise the prodromal phase of their crises to enable the day 1 blood sample to be obtained at an early stage. There have been few studies of the crisis prodrome ${ }^{12}$ although others have described an early phase of crisis in which rheological changes may precede the onset of pain. ${ }^{17}$ On day 1 , both C-reactive protein and SAA were already raised above the upper limit of the normal reference range in eight of 14 crises, but in only four crises were both tests increased above the upper limit of the range for that patient's steady state values. Creactive protein and SAA usually show an increase in blood concentration within six to 10 hours of tissue injury so that our day 1 values probably did reflect an early stage of the evolution of vaso-occlusion. ${ }^{56}$

This study shows a wide range in clinical severity and inflammatory response to tissue ischaemia of sickle cell crisis, including those episodes of pain that patients elect to treat at home. Objective markers of the evolution of this process are therefore required, particularly during the early (prodromal) stage of crisis when therapeutic intervention is more likely to be effective. A fast responding and sensitive marker of tissue ischaemia also allows resolution of crisis to be monitored, so 
that treatment can be regulated accordingly. These new immunoassays for C-reactive protein and SAA are identified as candidate markers that now require evaluation in a larger cohort of patients studied longitudinally. The acute phase response to tissue injury is known to be non-specific, however, and does not differentiate between infarction and infection either in sickle cell disease or in other disorders. ${ }^{18}$ Resolution of infection that accompanies sickle cell crisis can also be monitored using C-reactive protein and SAA, concentrations of which can fall with a halftime as fast as 24 hours following complete resolution of the provoking stimulus. ${ }^{19}$

We are indebted to The Wellcome Trust and the Medical Research Council for research Research Council for research grant support, to Dr IM Franklin and Dr MJ Leyland, who allowed us to study their
patients, to the sickle cell patients who volunteered for this patients, to the sickle cell patients who volunteered for this
study, and to Mrs SME Stevens for collecting blood specistudy, and to Mrs SME Stevens for collecting blood speci-
mens from them. The sialic acid kit was made available by the mens from them. The sialic acid kit was made available by the
kindness of Professor $Y$ Isogai and Professor $M$ Machida, Jikei University School of Medicine, Tokyo.

1 Murray N, May A. Painful crises in sickle cell diseasepatients' perspectives. $\mathrm{Br}$ Med f 1988;297:452-4.

2 Akinola NO, Stevens SME, Franklin IM, Nash GB Stuart J. Rheological changes in the prodromal and Stuart J. Rheological changes in the prodromal and established phases of sickle cell

3 Akinola NO, Stevens SME, Franklin IM, Nash GB, Stuart J. Subclinical ischaemic episodes during the steady state of sickle cell anaemia. F Clin Pathol 1992; 45:902-6.

4 Singhal A, Doherty JF, Raynes JG, et al. Is there an acute phase response in steady-state sickle cell disease? Lancet 1993;341:651-3.
5 Pepys MB, Baltz ML. Acute phase proteins with special reference to $C$-reactive protein and related proteins (pentaxins) and serum amyloid A protein. Adv Immunol (pentaxins) and se

6 International Committee for Standardization in Haematology (Expert Panel on Blood Rheology) Guidelines on selection of laboratory tests for monitoring the acute phase response. F Clin Pathol 1988;41: 1203-12.

7 de Beer FC, Pepys MB. Isolation of human C-reactive protein and serum amyloid $\mathrm{P}$ component. $\mathcal{F}$ Immunol Methods 1982;50:17-31.

8 Shine B, de Beer FC, Pepys MB. Solid phase radioimmunoassays for C-reactive protein. Clin Chim Acta 1981;117:13-23.

9 Sugahara K, Sugimoto K, Nomura O, Usui T. Enzymatic assay of serum sialic acid. Clin Chim Acta 1980;108: assay of

10 Warren C, Whicher J, Kohn J. The use of concanavalin A to measure acute phase proteins by laser nephelometry. f Immunol Methods 1980;32:141-50.

11 Neely CL, Wajima T, Kraus AP, Diggs LW, Barreras L. Lactic acid dehydrogenase activity and plasma hemoglobin elevations in sickle cell disease. Am $f$ Clin Pathol 1969;52:167-9.

12 Hunt BJ, Korsah P, Eaton S, Brozovic M. Creatine kinase activity in sickle cell disease. F Clin Pathol 1989;42: 712-5.

13 Famodu AA, Adedeji MO, Reid HL. Serial plasma fibrinogen changes accompanying sickle cell pain crisis.

14 Laogun AA, Ajayi NO, Osamo NO, Okafor LA. Plasma viscosity in sickle-cell anaemia. Clin Phys Physiol Meas 1980;1:145-50

15 Sabio H, McKie VC. Modified (mixed) erythrocyte sedimentation rate in sickle cell anemia. Clin Hemorheol 1992;12:587-92.

16 Waters PJ, Lewry E, Pennock CA. Measurement of sialic acid in serum and urine: clinical applications and limitations. Ann Clin Biochem 1992;29:625-37.

17 Ballas SK, Smith ED. Red blood cell changes during the evolution of the sickle cell painful crisis. Blood 1992; evolution of

18 Becton DL, Raymond L, Thompson C, Berry DH. Acutephase reactants in sickle cell disease. $\mathcal{F}$ Pediatr 1989; 115:99-102.

19 Cox ML, Rudd AG, Gallimore R, Hodkinson HM, Pepys MB. Real-time measurement of serum C-reactive protein in the management of infection in the elderly. Age Ageing 1986;15:257-66. 